(อ)

OPEN ACCESS

\title{
Development of pyogenic granuloma with strong vascular endothelial growth factor receptor-2 expression during ramucirumab treatment
}

\author{
Tatsuya Ibe, ${ }^{1}$ Yoichiro Hamamoto (D) , ' Mikage Takabatake, ${ }^{2}$ Shingo Kamoshida ${ }^{2}$
}

Department of Pulmonary Medicine, National Hospital Organization Nishisaitama-Chuo National Hospital, Tokorozawa, Japan

Laboratory of Pathology, Department of Medical Biophysics, Kobe University Faculty of Health Sciences and Graduate School of Medicine Faculty of Health Sciences, Kobe, Hyogo, Japan

\section{Correspondence to} Dr Yoichiro Hamamoto; hamamoto32@gmail.com

Accepted 15 November 2019

Check for updates

(c) BMJ Publishing Group Limited 2019. Re-use permitted under CC BY-NC. No commercial re-use. See rights and permissions. Published by BMJ.

To cite: Ibe T, Hamamoto $Y$, Takabatake M, et al. BMJ Case Rep 2019:12:e231464. doi:10.1136/bcr-2019231464

\section{SUMMARY}

The angiogenesis inhibitor ramucirumab (IMC-1121B) is a fully humanised $\lg G 1$ monoclonal antibody targeting the extracellular domain of vascular endothelial growth factor receptor 2. Ramucirumab has been approved as a second-line treatment for lung cancer. Pyogenic granuloma is an acquired, benign vascular tumour of the skin or mucous membrane. We encountered a patient with pyogenic granuloma who was treated with ramucirumab. The patient was a 48-year-old Japanese woman with advanced lung cancer who had been heavily pretreated using several lines of chemotherapy. Ramucirumab was administered as the fifth-line treatment with docetaxel. After 10 days, a painless ricecoloured or pink papule appeared on her finger. One month later, it increased in size to $20 \mathrm{~mm}$. We examined the pathological condition by immunostaining using the resected specimen diagnosed as pyogenic granuloma. Paradoxically, this vascular tumour arose during the administration of an angiogenesis inhibitor.

\section{BACKGROUND}

Pyogenic granuloma (PG) is an acquired, benign vascular tumour of the skin or mucous membrane. PG is considered a reactive tumour-like lesion, arising from various stimuli, such as chronic low-grade irritation, traumatic injury, hormones or drug-induced reactions. PG development during chemotherapy has rarely been reported, including only one known case of PG development during ramucirumab administration, ${ }^{1}$ where a KDR (vascular endothelial growth factor receptor-2 (VEGFR2)) p.T771R mutation was detected, although VEGFR2 expression was not evaluated. Therefore, in this study, the expression of VEGFR2 was evaluated by immunohistochemistry in a rare case of PG arising during ramucirumab administration.

\section{CASE PRESENTATION}

A 48-year-old woman was referred to us due to a chest abnormality detected during an annual health examination in March 2012. A chest CT scan showed a mass in the left lower lobe, along with the presence of pleural nodules. Diagnostic transbronchial lung biopsy showed pulmonary adenocarcinoma classified as stage IV (T4N3M1a). Combination chemotherapy with carboplatin and pemetrexed plus bevacizumab was started; however, an ALK fusion gene mutation was detected during the initial treatment. The disease returned after first-line treatment, and the patient was sequentially treated with crizotinib, alectinib and nivolumab. Ten days after the administration of docetaxel and ramucirumab, a painless rice-to-pinkcoloured papule appeared on the right thumb distal interphalangeal joint. The tumour bled occasionally and did not shrink. One month later, it increased in size to $20 \mathrm{~mm}$ (figure 1 ).

\section{OUTCOME AND FOLLOW-UP}

The tumour was surgically resected owing to a suspicious malignant metastasis. After PG resection, there was no recurrence. Unfortunately, docetaxel plus ramucirumab was discontinued due to progressive disease.

H\&E staining of the resected tissue specimen revealed an epidermis-covered protuberant lesion showing irregular proliferation. Histopathological findings were consistent with PG (figure 2A).

For immunostaining, heat-induced antigen retrieval was performed by incubating sections with $10 \mathrm{mM}$ Tris base containing $1 \mathrm{mM}$ ethylenediaminetetraacetic acid ( $\mathrm{pH}$ 9.0). To detect VEGFR2, a section was incubated with an anti-VEGFR2 rabbit monoclonal antibody (clone 55B11; Cell Signaling Technology, Danvers, Massachusetts, USA), followed by incubation with an anti-rabbit peroxidase polymer (Nichirei Bioscience, Tokyo, Japan). The reaction products were developed with a diaminobenzidine solution (Dako, Glostrup, Denmark). Thymidine kinase-1 (TK1) and cluster of differentiation (CD31) double immunostaining were performed using an anti-TK1 mouse monoclonal antibody (clone F12; Bio-Rad, Hercules, California, USA) and anti-CD31 rabbit monoclonal antibody (clone EP3095; Abcam, Cambridge,

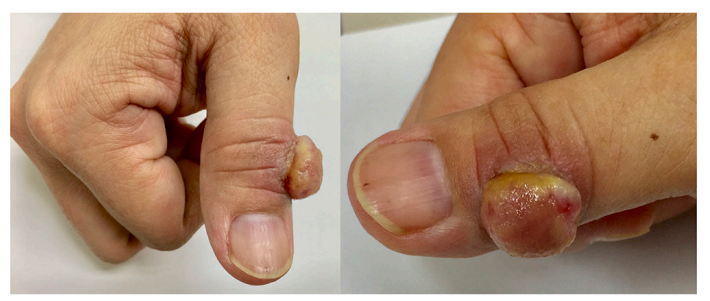

Figure 1 Pyogenic granuloma: macroscopic findings. A pedunculated tumour of approximately $20 \mathrm{~mm}$ was seen on the right thumb DIP joint. DIP, distal interphalangeal joint. 


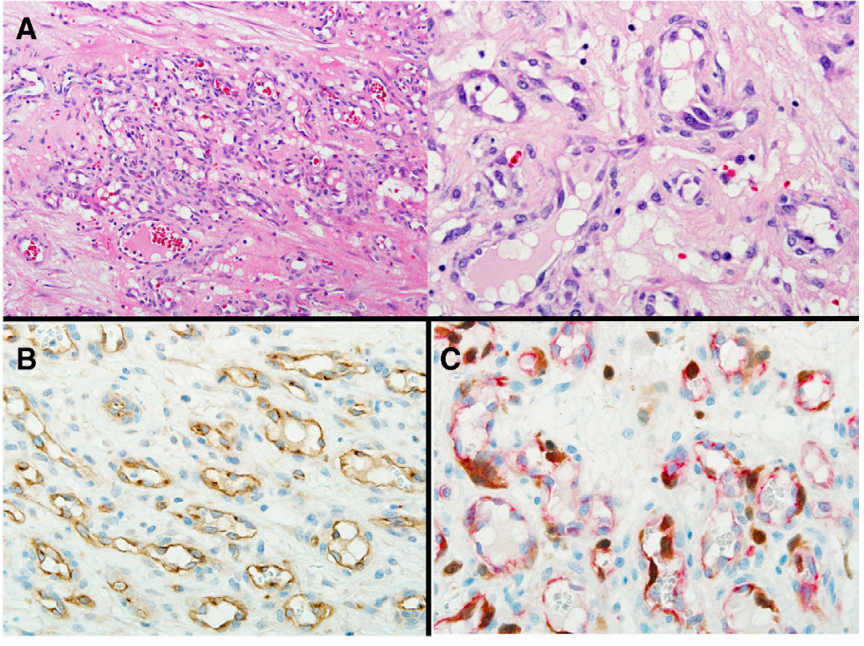

Figure 2 Pyogenic granuloma. Under the epidermis, capillary vessels showing leafy densification were observed. Vascular endothelial cells showed mild nuclear enlargement. Oedema, bleeding and mild inflammatory cell infiltration were seen in the interstitium. Malignant cells were not observed and findings were consistent with pyogenic granuloma $((A)$ H\&E staining; $\times 100$ (left), $\times 400$ (right)). Strong staining of VEGFR2 was observed in almost all vascular endothelial cells ((B) VEGFR2 immunostaining; $\times 400)$. TK1, a cell proliferation marker, was also frequently detected ((C) TK1/CD31 double immunostaining; $\times 400)$. VEGFR2, vascular endothelial growth factor receptor-2.

UK). Colours were developed using diaminobenzidine solution (Dako) for TK1 and Fuchsin + solution (Dako) for CD31.

Based on the immunostaining results, majority of the blood vessels were considered to be VEGFR2-positive (figure 2B). TK1, a proliferation marker, was also found to be strongly expressed in the nuclei of endothelial cells (figure 2C).

\section{DISCUSSION}

PG is an acquired, benign vascular tumour of the skin or mucous membrane. This hyperangiogenic lesion grows rapidly, and frequently appears as a haemorrhagic, red-purple, venous or perforating tumour mass. ${ }^{2}$ In children, $\mathrm{PG}$ is more common in boys than in girls; however, in adults, it is more common in women. ${ }^{34}$ Vascular tumours are commonly found in the face and limbs; however, their cause is not yet clear.

PG arises from various stimuli, including chronic low-grade irritation, traumatic injury, hormones and drugs. There are several reports of pharmaceutical PG associated with gefitinib or paclitaxel. ${ }^{56}$ Lim et al reported the development of PG under the administration of ramucirumab in $2015 .{ }^{1}$ They detected a mutation in $K D R$, which is a driver of vascular lesions and is frequently observed after angioplasty and in patients with angiosarcoma. ${ }^{17}$ Recently, there have been reports of 4 cases of PG onset using ramucirumab. ${ }^{8}$

In our case, although the KDR mutation status was not determined, positive staining for VEGFR2 was detected throughout the vascular tumour. In vitro study of angiosarcoma revealed KDR gene mutations to lead to autophosphorylation of KDR tyrosine kinase, and KDR-mutant tumours to uniformly express strong and diffused KDR protein as shown by immunohistochemistry. ${ }^{7}$ It is therefore possible that a KDR mutation leads to the overexpression of VEGFR2. Thus, the latter may be inferred from the anti-VEGF action of ramucirumab to promote PG. We also analysed TK1, an alternative cell proliferation marker to
Ki-67. ${ }^{9-11}$ We found many cells positive for TK1 by immunostaining, thus indicating the proliferation of vascular cells.

Based on PG occurrence in the fingers, we hypothesised that a small wound triggered VEGFR2 overexpression by a mutation in $K D R$ (p.T771R), which is a driver of vascular lesions, following ramucirumab administration. Positive TK1 staining suggested the vascular tumour to be growing rapidly.

There have been several reports of vascular tumour growth due to the use of angiogenesis inhibitors. However, despite the use of angiogenesis inhibitors, we found evidence for vascular tumour growth. VEGFR2 is likely to have been involved, owing to the concurrent ramucirumab administration.

In conclusion, we report a case of a vascular tumour (PG) during administration of the VEGFR2 inhibitor ramucirumab (an angiogenesis inhibitor). Therefore, during ramucirumab treatment, it is recommended to pay attention to the appearance of vascular lesions, which may occur at the sites of small wounds.

\section{Learning points}

- Pyogenic granuloma (PG) is an acquired, benign vascular tumour of the skin or mucous membrane.

- Positive staining for vascular endothelial growth factor receptor-2 (VEGFR2) was detected throughout the vascular tumour. The overexpression of VEGFR2 can be inferred from the anti-VEGF action of ramucirumab, promoting PG.

- During ramucirumab treatment, it would be important to pay attention to the appearance of vascular lesions.

Contributors YH designed the study and TI wrote the initial draft of the manuscript. MT and SK contributed to pathological analysis and interpretation of data and assisted in the preparation of the manuscript. All authors approved the final version of the manuscript and agree to be accountable for all aspects of the work in ensuring that questions related to the accuracy or integrity of any part of the work are appropriately investigated and resolved.

Funding This study was funded by Grant-in-Aid for Scientific Research Program from the Japan Society for the Promotion of Science (JSPS KAKENHI; Grant Number 16K08690).

Competing interests None declared.

Patient consent for publication Obtained.

Provenance and peer review Not commissioned; externally peer reviewed.

Open access This is an open access article distributed in accordance with the Creative Commons Attribution Non Commercial (CC BY-NC 4.0) license, which permits others to distribute, remix, adapt, build upon this work non-commercially, and license their derivative works on different terms, provided the original work is properly cited and the use is non-commercial. See: http://creativecommons.org/ licenses/by-nc/4.0/.

\section{ORCID iD}

Yoichiro Hamamoto http://orcid.org/0000-0002-2165-9475

\section{REFERENCES}

1 Lim YH, Odell ID, Ko CJ, et al. Somatic p.T771R KDR (VEGFR2) mutation arising in a sporadic angioma during ramucirumab therapy. JAMA Dermatol 2015;151:1240-3.

2 Harris MN, Desai R, Chuang T-Y, et al. Lobular capillary hemangiomas: an epidemiologic report, with emphasis on cutaneous lesions. J Am Acad Dermatol 2000;42:1012-6.

3 Akamatsu T, Hanai U, Kobayashi M, et al. Pyogenic granuloma: a retrospective 10-year analysis of 82 cases. Tokai J Exp Clin Med 2015;40:110-4.

4 Koo MG, Lee SH, Han SE. Pyogenic granuloma: a retrospective analysis of cases treated over a 10-year. Arch Craniofac Surg 2017;18:16-20.

5 High WA. Gefitinib: a cause of pyogenic granulomalike lesions of the nail. Arch Dermato/ 2006:142:939.

6 Paul LJ, Cohen PR. Paclitaxel-associated subungual pyogenic granuloma: report in a patient with breast cancer receiving paclitaxel and review of drug-induced 


\section{Findings that shed new light on the possible pathogenesis of a disease or an adverse effect}

pyogenic granulomas adjacent to and beneath the nail. J Drugs Dermatol 2012:11:262-8.

7 Antonescu CR, Yoshida A, Guo T, et al. KDR activating mutations in human angiosarcomas are sensitive to specific kinase inhibitors. Cancer Res 2009;69:7175-9.

8 Watanabe R, Nakano E, Kawazoe A, et al. Four cases of paradoxical cephalocervical pyogenic granuloma during treatment with paclitaxel and ramucirumab. J Dermatol 2019:46:e178-80.
9 Wang J, Liu Q, Zhou X, et al. Thymidine kinase 1 expression in ovarian serous adenocarcinoma is superior to Ki-67: a new prognostic biomarker. Tumour Biol 2017;39.

10 Zhou J, He E, Skog S. The proliferation marker thymidine kinase 1 in clinical use. Mol Clin Oncol 2013;1:18-28.

11 Okamura S, Osaki T, Nishimura K, et al. Thymidine kinase-1/CD31 double immunostaining for identifying activated tumor vessels. Biotech Histochem 2019:94:60-4.

Copyright 2019 BMJ Publishing Group. All rights reserved. For permission to reuse any of this content visit https://www.bmj.com/company/products-services/rights-and-licensing/permissions/

BMJ Case Report Fellows may re-use this article for personal use and teaching without any further permission.

Become a Fellow of BMJ Case Reports today and you can:

- Submit as many cases as you like

Enjoy fast sympathetic peer review and rapid publication of accepted articles

Access all the published articles

Re-use any of the published material for personal use and teaching without further permission

Customer Service

If you have any further queries about your subscription, please contact our customer services team on +44 (0) 2071111105 or via email at support@bmj.com.

Visit casereports.bmj.com for more articles like this and to become a Fellow 